\title{
Coordination of FACTS controllers for damping improvement in power system
}

\author{
Md. Ismail Haque ${ }^{1}$, Md. Lokman Hossain ${ }^{2}$, Md. Rasheduzzaman ${ }^{3}$, M S \\ Anower $^{4}$, M A Rafiul Faisal ${ }^{5}$ \\ 1, 2,3 (EEE, IIUC, Bangladesh) \\ 4, 5 (EEE, RUET, Bangladesh)
}

\begin{abstract}
Damping improvement is very much important in power system. One of the major criteria, deciding the power system operation is the system stability. It is the ability to maintain the machines connected to the system in synchronism. But disturbances consistently happen either due to the sudden addition or removal of load, short circuit of lines, lightning etc. Therefore lack of sufficient damping leads to oscillatory behavior of machine output quantities and instability. FACTS devices enhance this damping and insure stability of the power system. This paper investigates the optimization and coordination of the conventional FACTS (SSSC, STATCOM and UPFC) with POD controller in order to improve the damping and stability of a power system.
\end{abstract}

Keywords: FACTS; damping; Static Synchronous Series Compensator (SSSC); POD; Unified Power Flow Controller (UPFC); Static Compensator (STATCOM).

\section{Introduction}

In current world power demand is increasing substantially but the expansion and transmission are limited by many factors such as resources and environmental restrictions. As a consequence, some transmission lines are heavily loaded and the system stability becomes a power transfer-limiting factor. Lack of sufficient damping causes oscillatory behavior and instability in machine output. Electromechanical oscillations have been observed in many power systems worldwide [1].Damping of power system oscillation had been a matter of concern from the very past. Flexible AC transmission systems (FACTS) controllers have been mainly used for solving various power system steady state control problems. However, recent studies reveal that FACTS controllers could be employed to enhance power system stability in addition to their main function of power flow control. Conventional FACTS damping controllers that have been widely used are Static Synchronous Series Compensator (SSSC), Static Compensator (STATCOM) and Unified Power Flow Controller (UPFC).

A Static Synchronous Series Compensator (SSSC) is a member of FACTS family which is connected in series with a power system. It contains solid state voltage source converter (VSC).This VSC generate a controllable $\mathrm{AC}$ voltage at fundamental frequency. When the injected voltage is kept in quadrature with the line current, it can emulate as inductive or capacitive reactance so as to influence the power flow through the transmission line [2-4]. A SSSC is used to control power flow in steady state but it can also be useful to improve transient stability of a power system. Static Compensator (STATCOM) is a second generation's shunt connected FACTS devices based on a voltage source converter (VSC) using GTOs [5]. To maintain the bus voltage STATCOM supply the required reactive power even at low bus voltages and improves the power swing damping. STATCOM has some advantages above conventional Static Var Compensation (SVC). The UPFC (Unified Power Flow Controller) is the most versatile and powerful FACTS device [6].UPFC can control the parameters in the transmission line such as line impedance, terminal voltages, and voltage angle. In transmission lines it has been used for independent control of real and reactive power. Moreover, the UPFC can be used for voltage support and damping of electromechanical oscillations [7-8]. In this paper the study is concentrated on the investigating of optimization and coordination of the conventional FACTS damping controllers (SSSC, STATCOM and UPFC) in purpose with the improvement of damping and stability of power system using POD controller.

\section{Modeling Of Different Technique}

In this study a proposal has been supposed to coordinate the FACT controllers for damping improvement in power system. In the FACT family SSSC is connected in series with power system and it is used for emulation of inductive and capacitive reactance which control power flow in steady state. It can be also useful to improve transient stability. STATCOM is second generation shunt connected member of FACT's family. It supplies the required reactive power even at low bus voltages and improves the power swing damping. UPFC is one of the versatile and powerful FACT devices. It controls line impedance, terminal voltages, and voltage angle in transmission line. It can also be used for voltage support and damping of electromechanical 
oscillations. There is another problem of oscillatory behavior of machine output quantities and instability which caused by insufficient damping. This phenomenon is overcome by using POD controller on Bus bar system. Figure 1 Shows designed 4-bus interconnected power system model with 3-loads.

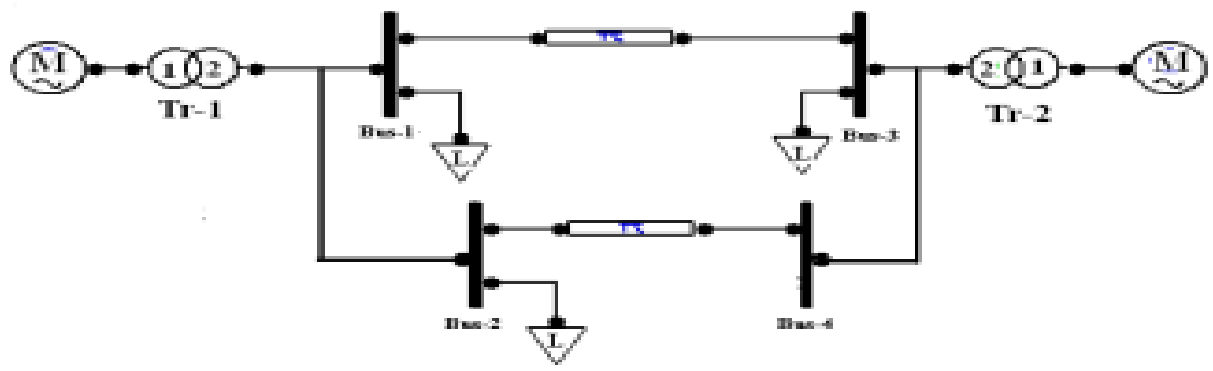

Figure 1: 4 BUS interconnected power system with 3 loads.

\section{Coordination Of Facts Controller}

Nowadays, FACTS devices are used to control power flow and to enhance system stability [9].Damping of power system oscillation in areas those are interconnected has importance to secure the system operation. FACTS devices are applied for the extension of system stability where PODC used for sufficient damping oscillation.

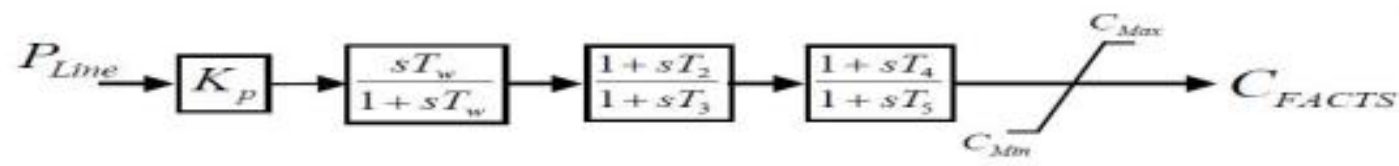

Figure 2: POD controller.

The structural design of POD controller is shown in figure 2. From the figure it has been illustrated that it involves transfer function consist of an amplification block, a wash out block and two lead lag blocks.

\section{A. System AnAlysis Without Pod CONTROLleR}

Before the POD controller is integrated into the power system the system is analyzed first without POD controller to obtain knowledge of the inherent dynamics of the power system. The system is studied in both the power angle and the time domain. Figure 3 shows the dynamic response of machine- 1 and figure 4 shows the dynamic response of machine-2 in bus bar system UPFC without POD controller. Figure 5 shows the dynamic response of machine-1 and figure 6 shows the dynamic response of machine-2 in bus bar system STATCOM without POD controller.

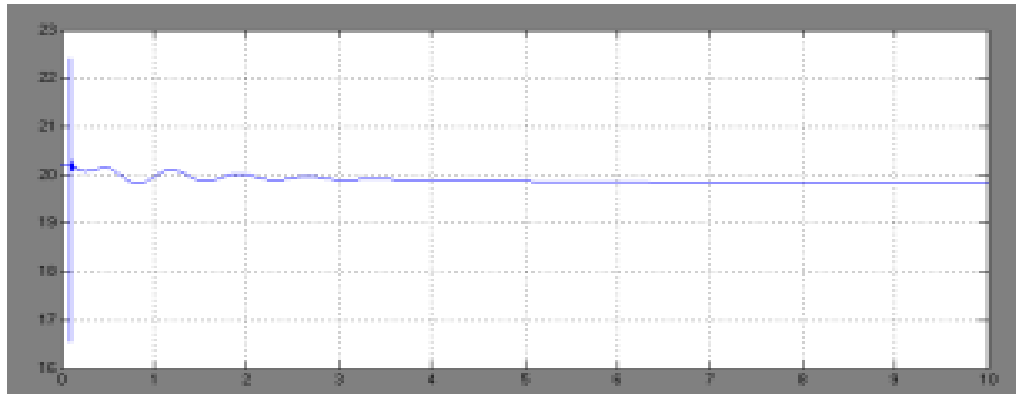

Figure 3: Without POD UPFC for Machine 1(Power Angle VS Time)

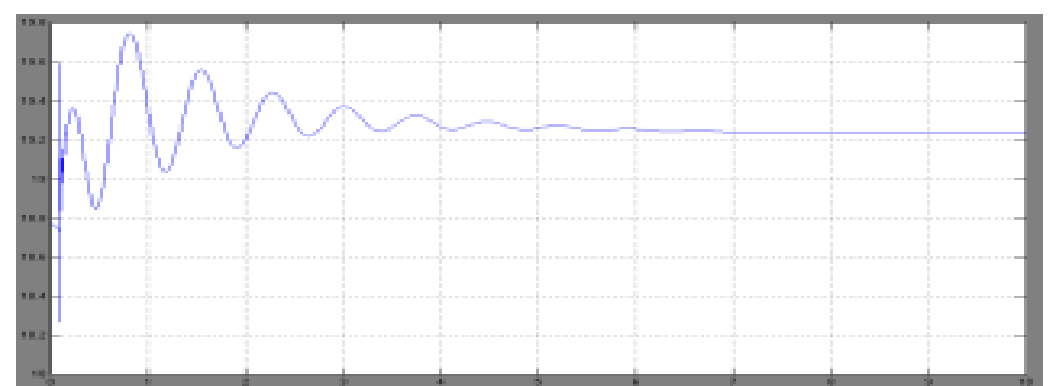

Figure 4: Without POD UPFC for Machine 2(Power Angle VS Time) 


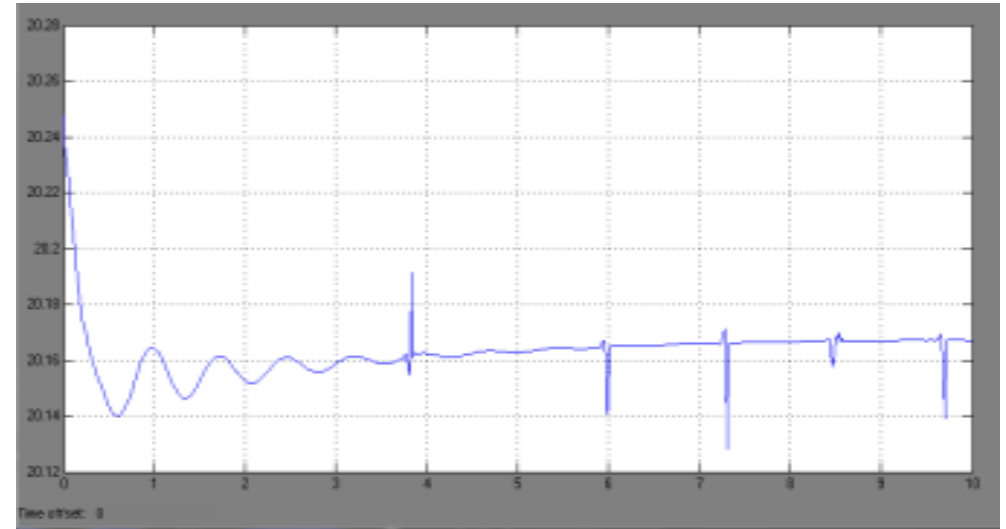

Figure 5: Without POD STATCOM for Machine 1(Power Angle VS Time)

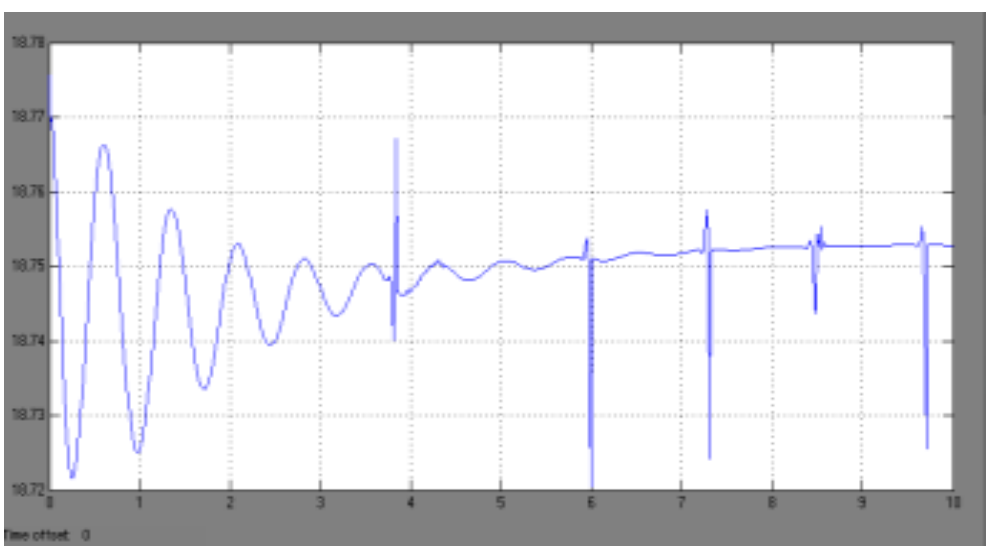

Figure 6: Without POD STATCOM for Machine 2(Power Angle VS Time)

\section{B. System Analysis With Pod Controller}

Purpose of installing FACTS devices is issue of steady state, dynamic problems or both. But for the sufficient damping oscillation issue POD controller have to introduce. A POD controller has been integrated in a bus bar system in series with a FACT device is shown in figure 7. The system is studied in both the power angle and the time domain. Figure 8 shows the dynamic response of machine- 1 and figure 9 shows the dynamic response of machine-2 in bus bar system UPFC without POD controller. Figure 10 shows the dynamic response of machine-1 and figure 11 shows the dynamic response of machine- 2 in bus bar system STATCOM without POD controller.

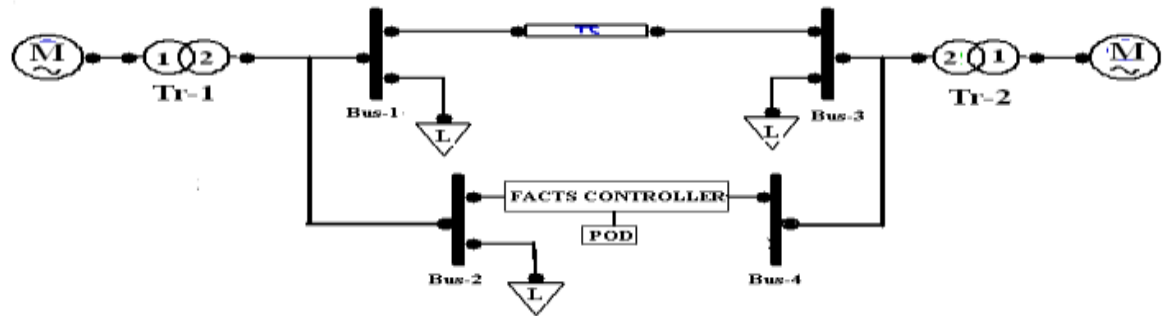

Figure 7: BUS interconnected power system with 3 load integrating POD

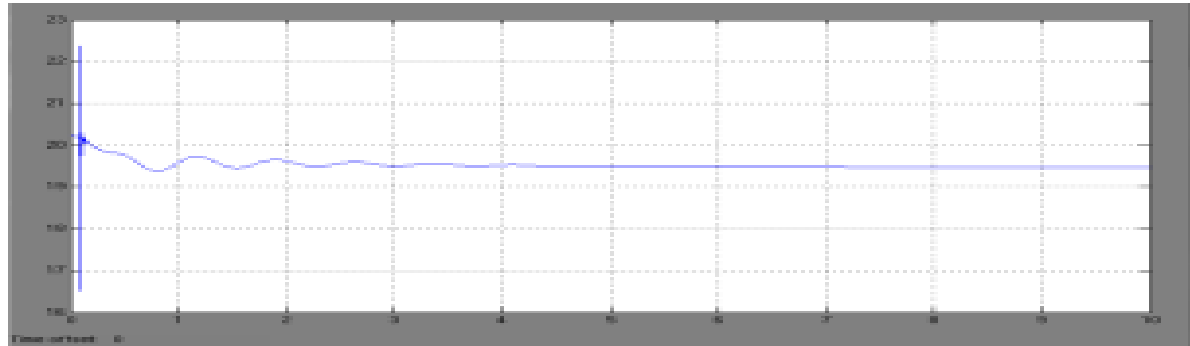

Figure 8: With POD-UPFC for Machine 1(Power Angle VS Time) 


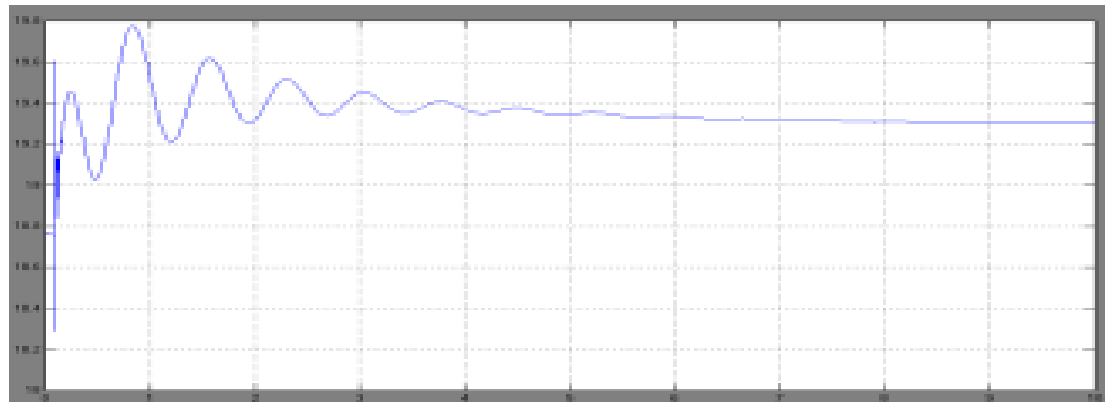

Figure 9: With POD-UPFC for Machine 2(Power Angle VS Time)

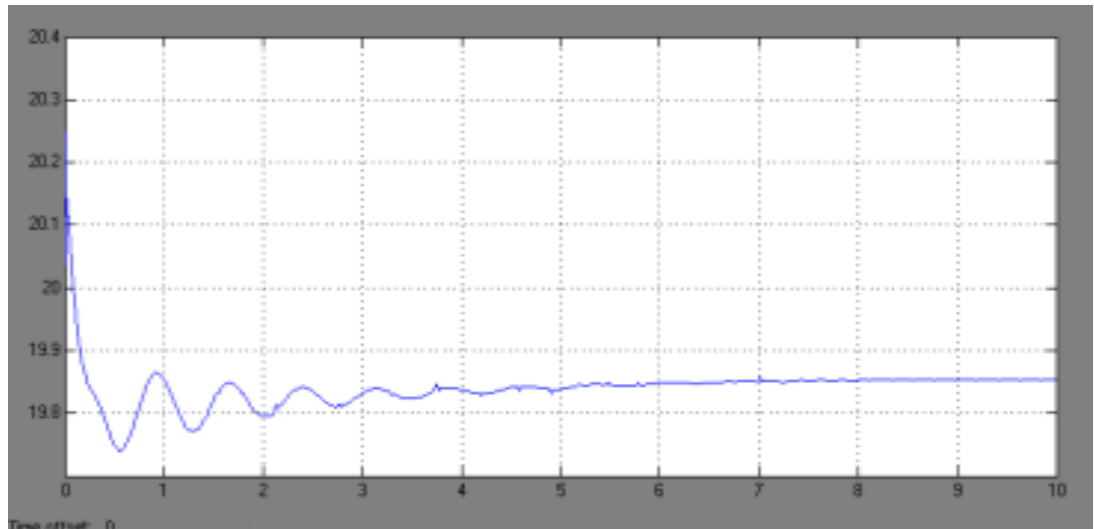

Figure 10: With POD STATCOM for Machine 1(Power Angle VS Time)

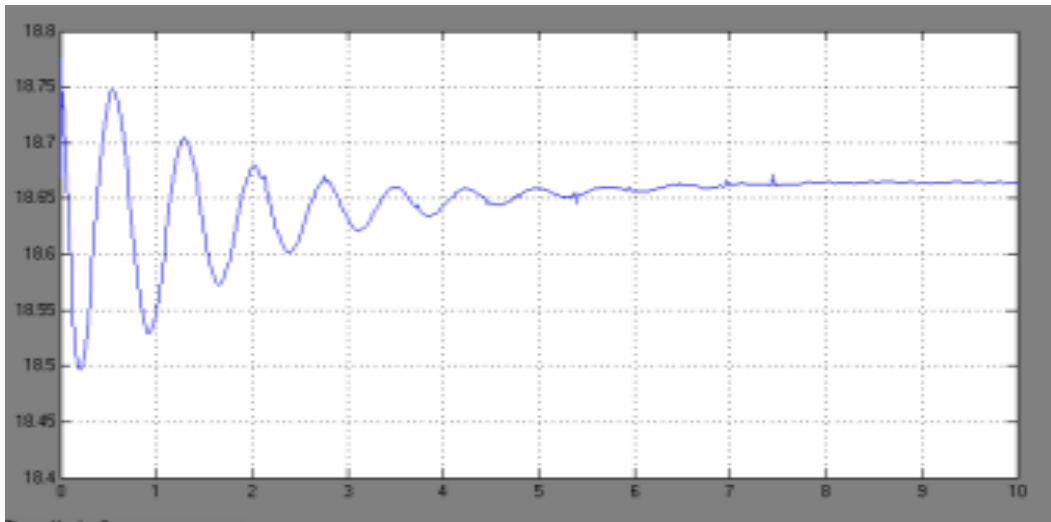

Figure 11: With PODSTATCOM for Machine 2(Power Angle VS Time)

It is clearly observed from the simulation results that with the developed controller the dynamic performance of the power system is quite improved with the incorporation of POD coordination scheme. It is also observed that with the controller, the power angle characteristics curves exhibit very less overshoots \& undershoots. It is also observed that the better performance of using POD can be understood easily but for UPFC the effect is small. The reason behind this is that UPFC incorporates both SSSC and STATCOM therefore its performance is better than SSSC and STATCOM.

\section{Conclusion}

Simulation results have yield information on the performance of using of PODC with SSSC, STATCOM and UPFC for a practical application. For a fault the SSSC, STATCOM and UPFC damps the oscillations quickly and minimizes or removes the unwanted overshoots due to the post fault effect on the load angle when performing with PODC than without PODC. Thus improves the transient stability as well as damping stability of The Power System. 


\section{References}

[1]. Rogers, G. (2012). Power system oscillations. Springer Science \& Business Media.

[2]. Sen, K. K. (1998). SSSC-static synchronous series compensator: theory, modeling, and application. IEEE Transactions on Power Delivery, 13(1), 241-246.

[3]. Mathur, R. M., \& Varma, R. K. (2002). Thyristor-based FACTS controllers for electrical transmission systems. John Wiley \& Sons.

[4]. Murali, D., Rajaram, D. M., \& Reka, N. (2010). Comparison of FACTS devices for power system stability enhancement. International Journal of Computer Applications, 8(4), 30-35.

[5]. Bamasak, S. M., \& Abido, M. A. (2005, August). Robust coordinated design of PSS \& STATCOM controllers for damping power system oscillation. InPOWER SYSTEMS COMPUTATION CONFERENCE (Vol. 15, pp. 22-26).

[6]. Cai, L. J., Erlich, I., \& Stamtsis, G. (2004, October). Optimal choice and allocation of FACTS devices in deregulated electricity market using genetic algorithms. In Power Systems Conference and Exposition, 2004. IEEE PES(pp. 201-207). IEEE.

[7]. Pounraj, K., Rajasekaran, V., \& Selvaperumal, S. (2012). INTERNATIONAL JOURNAL OF ELECTRICAL ENGINEERING \& TECHNOLOGY (IJEET).Journal Impact Factor, 3(1), 226-234.

[8]. Kumar, D. R., \& Kiran, N. R. (2013, November). Hybrid Controller Based UPFC for Damping of Oscillations in Multi Machine Power Systems. International Journal of Engineering Research and Technology (Vol. 2, No. 10 (October-2013)). ESRSA Publications.

[9]. Cai, L., \& Erlich, I. (2004). Coordination between transient and damping controller for series Facts devices using ANFIS technology. Power Plants and Power Systems Control 2003, 293 